\title{
Impact on Quality of Life after Treatment with Proton Pump Inhibitor in Laryngopharyngeal Reflux
}

\author{
Hae-Won Choi, Hyun-Woong Jun, Jin Hyuk Jung, \\ Moo Keon Kim, Kyung Tae, and Yong Bae Ji \\ Department of Otolaryngology-Head and Neck Surgery, College of Medicine, Hanyang University, Seoul, Korea
}

\author{
인후두 역류질환에서 양성자 펌프 억제제 치료가 삶의 질에 미치는 영향 \\ 최해원 · 전현웅 · 정진혁 · 김무건 · 태 경 · 지용배 \\ 한양대학교 의과대학 이비인후-두경부외과학교실
}

Received December 28, 2019

Revised February 13, 2020

Accepted February 17, 2020

Address for correspondence

Yong Bae Ji, MD, PhD

Department of Otolaryngology-

Head and Neck Surgery,

College of Medicine,

Hanyang University,

222 Wangsimni-ro, Seongdong-gu,

Seoul 04763, Korea

Tel $+82-2-2290-8585$

Fax $+82-2-2293-3335$

E-mail jyb20000@hanyang.ac.kr
Background and Objectives Several studies have assessed the impact of laryngopharyngeal reflux disease (LPRD) on the health-related quality of life (HR-QoL), showing significant impairment of HR-QoL. This study aims to assess the impact of proton pump inhibitor (PPI) treatment of LPRDs to enhance HR-QoL.

Subjects and Method We prospectively collected data from LPRD patients from April 2017 to July 2019. Patients who have reflux symptom index (RSI) of $\geq 13$ or reflux finding score (RFS) of $\geq 7$ were enrolled in this study. We assessed HR-QoL using a questionnaire with EORTC QLQ-H\&N35, -C30 on the first visit. Patients were treated with PPI (Ilaprazole $20 \mathrm{mg} /$ day) on their visits at 4,8 , and 12 weeks. RSI and RFS were measured at each visit and HR-QoL was reevaluated on the last visit.

Results Ninety-five patients completed the 3-months follow-up and were enrolled in this study. Female : male ratio was $71: 24$ and the mean age was $57.0 \pm 11.9(27-80)$. The initial RSI and RFS were $16.3 \pm 8.8$ and $12.6 \pm 2.9$, respectively, but were changed to $11.1 \pm 9.7$ and $9.7 \pm 2.6$ $(p<0.001$ in both) at 12 weeks after the treatment. Global health status/QoL, speech problem, dry mouth, and coughing were significantly improved.

Conclusion PPI administration is effective in treating LPRD, where effects begin to appear at 4 weeks after treatment. HR-QoL was also improved in patients who have RSI improvement. Korean J Otorhinolaryngol-Head Neck Surg 2020;63(11):517-22

Key Words Laryngopharyngeal reflux · Laryngoscopy · Proton pump inhibitor · Quality of life.

\section{서 론}

인후두 역류질환(laryngopharyngeal reflux disease)은 위장 속의 내용물의 인두, 후두 내로의 역행성 움직임으로 인해 목소리의 변화, 기침, 후두의 부종 등과 같은 증상을 일 으키는 질환으로 정의된다. ${ }^{1)}$ 주로 외래진료 환경에서 후두

This is an Open Access article distributed under the terms of the Creative Common Attribution Non-Commercial License (https://creativecommons.org/licenses/by-nc/4.0) which permits unrestricted non-commercial use, distribution, and reproduction in any medium, provided the original work is properly cited.
자극 증상 또는 후두자극의 특징적인 내시경 소견으로 인후 두 역류질환을 진단할 수 있으며 이비인후과를 방문하는 환 자들의 $10 \%$ 를 차지할 만큼 흔하게 접할 수 있는 질환 중 하 나다..$^{2-5)}$ 하지만 상대적으로 비특이적인 신체진찰 소견과 다 른 질환들과 중첩되는 증상들로 인해 인후두 역류질환의 진 단에 대한 기준에는 다소 논란이 있는 것이 현실이다. 인후 두 역류질환 진단을 받은 환자들의 $50 \%$ 이상은 만성 기침과 음성의 변화는 물론 일상생활에서의 다양한 불편감을 호소 하는데 이전 몇몇 연구결과에 따르면 인후두 역류질환은 동 
Table 1. Reflux symptom index and reflux finding score

\begin{tabular}{|c|c|}
\hline \multicolumn{2}{|l|}{ Reflux symptom index } \\
\hline 1. Hoarseness or a problem with your voice & $0=$ No problem \\
\hline 2. Clearing your throat & $5=$ Sever problem \\
\hline \multicolumn{2}{|l|}{ 3. Excess throat mucus or postnasal drip } \\
\hline \multicolumn{2}{|l|}{ 4. Difficulty swallowing food, liquids, or pills } \\
\hline \multicolumn{2}{|l|}{ 5. Coughing after you ate or after lying down } \\
\hline \multicolumn{2}{|l|}{ 6. Breathing difficulties or choking episodes } \\
\hline \multicolumn{2}{|l|}{ 7. Troublesome or annoying cough } \\
\hline \multicolumn{2}{|c|}{ 8. Sensations of something sticking in your throat or a lump in your throat } \\
\hline \multicolumn{2}{|c|}{ 9. Heartburn, chest pain, indigestion, or stomach acid coming up } \\
\hline \multicolumn{2}{|l|}{ Reflux finding score } \\
\hline Subglottic edema & $0=$ Absent, $2=$ present \\
\hline Ventricular obliteration & $0=$ Absent, $2=$ partial, $4=$ complete \\
\hline Erythema/hyperemia & $0=$ Absent, $2=$ arytenoid only, $4=$ diffuse \\
\hline Vocal cord edema & $0=$ Absent, $1=$ mild, $2=$ moderate, $3=$ severe, $4=$ polypoid \\
\hline Diffuse laryngeal edema & $0=$ Absent, $1=$ mild, $2=$ moderate, $3=$ severe, $4=$ obstructing \\
\hline Poterior commissure hypertrophy & $0=$ Absent, $1=$ mild, $2=$ moderate, $3=$ severe \\
\hline Granuloma/granulation tissue & $0=$ Absent $2=$ present \\
\hline Thick endolaryngeal mucus & $0=$ Absent, $2=$ present \\
\hline
\end{tabular}

반되는 증상에 따른 불편감 이외에도 환자들의 심리적인 상 태 및 사회적 기능이 저해요인으로 작용함으로써 삶의 질에 부정적 영향을 끼치는 것으로 알려져 있다. ${ }^{6-10)}$ 따라서 인후 두 역류질환의 치료에 있어서 질환과 연관된 증상의 개선은 물론 환자들의 삶의 질을 향상시키는데 치료에 목적을 둘 필 요가 있다. 본 연구의 목적은 양성자 억제제를 이용한 치료가 인후두 역류질환 환자의 증상 및 소견과 건강 관련 삶의 질 (health-related quality of life)에 미치는 영향에 대해 평가 하고자 하였다.

\section{대상 및 방법}

본 연구에서는 2017년 4월 2019년 7월까지 한양대학교 구리 병원 이비인후과 외래를 내원한 환자들 중 인후두 역류질환으 로 진단받은 환자 131명을 대상으로 전향적 연구를 시행하였 다. 진단은 Belafsky 등,3)이 제안한 후두내시경을 이용한 역류 소견점수(reflux finding score, RFS)와 역류증상지수(reflux symptom index, RSI)를 이용하였다(Table 1). RSI가 13점 이 상이거나 RFS가 7점 이상인 경우 인후두 역류질환으로 진단 하였다. 대상환자 중 약물 과민, 이전 소화기계 수술력, 두경부 종양의 기왕력, 두경부 방사선 조사의 기왕력, 임산부, 수유부 는 제외하였다.

선정된 대상자는 설문지를 통해 치료전 삶의 질에 대한 평 가가 이루어졌으며(visit 0), 평가도구는 EORTC QLQ-HN35 및 QLQ-C30 설문지의 한국어 버전을 이용하였다. 모든 대
Table 2. Clinical characteristic of patients

\begin{tabular}{lc}
\hline \multicolumn{1}{c}{ Variables } & $\mathrm{n}=95$ \\
\hline Age & $57.0 \pm 11.9$ \\
Sex & \\
$\quad$ Male & $24(25.3)$ \\
$\quad$ Female & $71(74.7)$ \\
Initial assessment & \\
$\quad$ Reflux symptom index & $16.3 \pm 8.8$ \\
$\quad$ Reflux finding score & $12.6 \pm 2.9$ \\
Compatible with diagnosis (double count) \\
RSI $\geq 13$ & $58(61.1)$ \\
RFS $\geq 7$ & $80(84.2)$ \\
\hline
\end{tabular}

상자는 식이조절을 포함한 생활습관 개선에 대한 교육을 치 료가 시작할 때 안내서와 함께 제공받았으며, 12주간 Ilaprazole $20 \mathrm{mg}$ 을 하루 2회에 나누어 식전에 투약 받았다. 투여시 작 4주 후(visit 1), 8주 후(visit 2), 12주 후(visit 3)에 외래 내 원하였고 매 방문시 후두내시경을 시행하여 RFS를 평가하고 설문지를 통해 RSI를 측정하였다. 모든 후두내시경 검사 및 $\mathrm{RFS}$ 측정은 1 명의 두경부외과 전문의가 시행하였다. 12 주후 마지막 방문에 삶의 질을 다시 평가하였다.

본 연구는 연구자 주도 임상시험으로 본원 기관생명윤리위 원회의 승인을 얻어 진행하였으며(HYUG-2017-06-007), 자 료에 대한 통계 분석은 SPSS V22.0(IBM Corp., Armonk, $\mathrm{NY}, \mathrm{USA}$ )을 이용하여 치료전과 치료후의 RFS와 RSI 변화의 추이를 분석하였으며, 삶의 질의 차이를 paired T-검정을 이용 
Table 3. Changes of reflux symptom index

\begin{tabular}{lrrrrrrr}
\hline & Visit 0 & Visit 1 & Visit 2 & Visit 3 & \multicolumn{1}{c}{$\mathrm{p}^{*}$} & $\mathrm{p}^{\dagger}$ & $\mathrm{p}^{\ddagger}$ \\
\hline Reflux symptom index & $16.27 \pm 8.82$ & $13.89 \pm 9.01$ & $11.44 \pm 7.69$ & $11.07 \pm 7.76$ & 0.012 & $<0.001$ & $<0.001$ \\
Hoarseness & $2.01 \pm 1.63$ & $1.65 \pm 1.58$ & $1.38 \pm 1.32$ & $1.35 \pm 1.48$ & 0.063 & 0.006 & 0.015 \\
Throat clearing & $2.40 \pm 1.65$ & $2.28 \pm 1.47$ & $1.86 \pm 1.24$ & $1.87 \pm 1.34$ & 0.888 & 0.073 & 0.226 \\
Postnasal drip & $1.94 \pm 1.67$ & $1.72 \pm 1.63$ & $1.50 \pm 1.39$ & $1.39 \pm 1.36$ & 0.875 & 0.120 & 0.114 \\
Difficulty swallowing & $0.86 \pm 1.20$ & $0.75 \pm 1.14$ & $0.57 \pm 1.01$ & $0.63 \pm 1.08$ & 0.365 & 0.117 & 0.085 \\
Coughing & $1.12 \pm 1.44$ & $0.94 \pm 1.33$ & $0.86 \pm 1.12$ & $0.72 \pm 0.81$ & 0.202 & 0.916 & 0.633 \\
Breathing difficulty & $1.06 \pm 1.55$ & $0.76 \pm 1.20$ & $0.43 \pm 0.91$ & $0.41 \pm 0.91$ & 0.081 & 0.002 & $<0.001$ \\
Troublesome cough & $1.60 \pm 1.45$ & $1.18 \pm 1.42$ & $1.04 \pm 1.21$ & $0.87 \pm 1.24$ & 0.003 & $<0.001$ & 0.000 \\
Lump sensation & $3.02 \pm 1.60$ & $2.61 \pm 1.65$ & $2.04 \pm 1.45$ & $1.89 \pm 1.43$ & 0.017 & $<0.001$ & $<0.001$ \\
Heartburn & $2.26 \pm 1.59$ & $2.00 \pm 1.58$ & $1.57 \pm 1.51$ & $1.46 \pm 1.33$ & 0.470 & 0.088 & 0.001 \\
\hline
\end{tabular}

* $p$ for visit 0 and visit $1,+p$ for visit 0 and visit $2, \neq p$ for visit 0 and visit 3

Table 4. Changes of reflux finding score

\begin{tabular}{lccccccc}
\hline & Visit 0 & Visit 1 & Visit 2 & Visit 3 & \multicolumn{1}{c}{$\mathrm{p}^{*}$} & $\mathrm{p}^{\dagger}$ & $\mathrm{p}^{\ddagger}$ \\
\hline Reflux finding score & $12.61 \pm 2.89$ & $11.70 \pm 2.98$ & $10.60 \pm 3.12$ & $9.68 \pm 2.58$ & $<0.001$ & $<0.001$ & $<0.001$ \\
Subglottic edema & $1.10 \pm 1.00$ & $1.06 \pm 1.01$ & $0.89 \pm 0.99$ & $0.60 \pm 0.90$ & 0.658 & 0.811 & 0.009 \\
Ventricular obliteration & $2.08 \pm 0.38$ & $2.06 \pm 0.34$ & $2.04 \pm 0.27$ & $1.98 \pm 0.16$ & 0.321 & 0.160 & 0.096 \\
Erythema/Hyperemia & $3.05 \pm 1.01$ & $2.77 \pm 0.98$ & $2.58 \pm 0.91$ & $2.25 \pm 0.78$ & 0.004 & 0.012 & 0.001 \\
Vocal fold edema & $1.68 \pm 0.71$ & $1.57 \pm 0.67$ & $1.42 \pm 0.63$ & $1.38 \pm 0.63$ & 0.020 & $<0.001$ & $<0.001$ \\
Diffuse laryngeal edema & $1.68 \pm 0.63$ & $1.61 \pm 0.64$ & $1.43 \pm 0.64$ & $1.43 \pm 0.68$ & 0.045 & 0.003 & $<0.001$ \\
Posterior commissure hypertrophy & $2.16 \pm 0.70$ & $2.09 \pm 0.70$ & $1.75 \pm 0.70$ & $1.65 \pm 0.70$ & 0.419 & 0.003 & 0.003 \\
Granuloma/Granulation & $0.13 \pm 0.49$ & $0.11 \pm 0.47$ & $0.15 \pm 0.53$ & $0.13 \pm 0.46$ & 0.321 & 0.318 & 0.324 \\
Thick endolaryngeal mucus & $0.75 \pm 0.97$ & $0.43 \pm 0.83$ & $0.34 \pm 0.73$ & $0.28 \pm 0.68$ & 0.004 & 0.008 & 0.002 \\
\hline
\end{tabular}

* $p$ for visit 0 and visit $1, t p$ for visit 0 and visit $2, \neq p$ for visit 0 and visit 3

하여 비교하였다. 통계학적 유의 수준은 $95 \%$ 이상 $(p$-value $<0.05)$ 으로 하였다.

\section{결 과}

연구대상은 인후두 역류질환으로 진단받은 131 명의 환자 가 포함되었으나 그 중 36 명의 추적이 소실되어 최종적으로 95명의 환자가 본 연구를 완료하였다. 그 중 남성은 24명 (25.3\%), 여성은 71명(74.7\%), 평균연령은 57.0 \pm 11.9 세였다. 전체 대상자들의 치료 전 평균 RSI와 RFS는 각각 $16.3 \pm 8.8$ 과 $12.6 \pm 2.9$ 였으며, 진단 기준에 따라 인후두 역류질환 진단 에 부합되는 RSI $\geq 13$ 이 58명(61.1\%)이었으며, RFS $\geq 7$ 이 80 명(84.2\%)이었다(Table 2).

치료 후 RSI의 변화는 visit 1(4주차)부터 평균 13.89 \pm 9.01 으 로 치료 전 평균 $16.27 \pm 8.82$ 과 통계적으로 유의한 차이를 보 였다 $(p=0.012)$. 각 항목별 분석에서는 기침과 이물감이 visit 1 (4주차)부터 치료 전과 유의한 차이를 보였으며, 애성, 호흡곤 란은 visit 2(8주차)부터, 가슴쓰림은 visit 3(12주차)부터 유의 한 차이를 보였다. 이에 반해 기도청소, 후비루, 연하곤란은 visit 3(12주차)까지 유의한 차이를 보이지 않았다(Table 3).
RFS 또한 visit 1 (4주차)부터 평균 $11.70 \pm 2.98$ 로 치료전 $12.61 \pm 2.89$ 와 유의한 수준의 감소가 관찰되었고 $(p<0.001)$, 각 항목별 분석에서는 후두 발적, 성대 부종, 미만성 후두 부 종, 후두내 객담이 visit 1 (4주차)부터 치료 전과 유의한 차이 를 보였으며, 후교련 비후는 visit 2(8주차)부터, 성문하 부종 은 visit 3(12주차)부터 유의한 차이를 보였다. 후두실 폐색과 후두 육아종은 유의한 차이를 보이지 않았다(Table 4).

삶의 질의 평가에서는 EORTC QLQ-C30 설문지를 이용 한 전반적 건강 상태/삶의 질(global health status/quality of life)은 치료 전 82.2에서 visit 3(12주 후)부터 88.2로 통계적 으로 유의하게 증가하였다 $(p=0.010)$. EORTC QLQ-HN35 를 활용하여 두경부 관련 삶의 질 항목의 변화를 평가한 결 과에서는 치료전과 비교하여 visit 3(12주차)에 언어기능 (speech problems), 구강 건조(dry mouth), 기침(cough), 아 프다는 느낌(felt ill) 항목에서 유의한 수준의 호전을 보인 것 으로 나타났다(Table 5).

\section{고 찰}

2002년 미국이비인후과학회는 성명서를 통해 인후두 역 
Table 5. Changes of health related QoL

\begin{tabular}{|c|c|c|c|}
\hline & Visit 0 & Visit 3 & $p$ \\
\hline \multicolumn{4}{|l|}{ EORTC-C30 } \\
\hline $\begin{array}{l}\text { Global health status } \\
\text { /QoL }\end{array}$ & $82.2 \pm 3.40$ & $88.2 \pm 5.01$ & 0.010 \\
\hline \multicolumn{4}{|l|}{ EORTC-H\&N35 } \\
\hline \multicolumn{4}{|l|}{ Symptom scales/items } \\
\hline Pain & $21.15 \pm 18.20$ & $10.90 \pm 9.25$ & 0.120 \\
\hline Swallowing & $5.77 \pm 9.25$ & $5.77 \pm 12.45$ & 1.000 \\
\hline Senses problems & $8.97 \pm 18.78$ & $6.41 \pm 16.01$ & 0.337 \\
\hline Speech problems & $24.79 \pm 27.65$ & $6.84 \pm 10.68$ & 0.024 \\
\hline $\begin{array}{l}\text { Trouble with } \\
\text { social eating }\end{array}$ & $4.49 \pm 9.99$ & $1.02 \pm 0.94$ & 0.131 \\
\hline $\begin{array}{l}\text { Trouble with } \\
\text { social contact }\end{array}$ & $3.08 \pm 4.40$ & $3.08 \pm 7.99$ & 1.000 \\
\hline Less sexuality & $14.10 \pm 29.54$ & $8.97 \pm 19.97$ & 0.337 \\
\hline Teeth & $25.64 \pm 27.74$ & $20.51 \pm 16.88$ & 0.549 \\
\hline Opening mouth & $7.69 \pm 14.62$ & $5.13 \pm 12.52$ & 0.337 \\
\hline Dry mouth & $51.28 \pm 29.24$ & $25.64 \pm 24.17$ & 0.001 \\
\hline Sticky saliva & $28.21 \pm 18.49$ & $17.95 \pm 25.88$ & 0.165 \\
\hline Coughing & $43.59 \pm 21.01$ & $23.08 \pm 21.01$ & 0.014 \\
\hline Felt ill & $30.77 \pm 34.59$ & $7.69 \pm 14.62$ & 0.013 \\
\hline Pain killers & $61.54 \pm 76.79$ & $30.77 \pm 63.04$ & 0.303 \\
\hline $\begin{array}{l}\text { Nutritional } \\
\text { supplements }\end{array}$ & $53.85 \pm 87.71$ & $30.77 \pm 48.04$ & 0.273 \\
\hline Weight loss & $23.08 \pm 43.85$ & $30.77 \pm 63.04$ & 0.673 \\
\hline Weight gain & $46.15 \pm 66.02$ & $30.77 \pm 48.04$ & 0.165 \\
\hline
\end{tabular}

QoL: quality of life

류질환은 병태생리, 증상, 역류의 패턴에 있어서 기존의 위식 도 역류질환(gastroesophageal reflux disease)과 다른 질환 임을 강조하였다. ${ }^{1)}$ 인후두 역류질환은 위식도 역류질환과 달 리 주로 주간에 서있는 상태에서 역류가 발생하며, 위식도 역 류질환에서는 식도 운동장애와 식도 산 청소가 감소한 반면 인후두 역류질환에서는 이런 것이 관찰되지 않아 위식도 역 류질환은 주로 하부식도 괄약근의 이상이 주 원인인 반면 인후두 역류질환에서는 상부식도 괄약근의 기능 부전이 원 인이라고 보고되고 있다.5,11) 따라서 인후두 역류질환의 증상 은 주로 상부 소화호흡기관의 기능부전의 형태로 나타나며 인두 청소행위(throat clearing), 만성 기침, 흥부작열감, 소 화불량, 인두 이물감, 음성변화, 발성 장애 등의 증상으로 나 타나게 된다. ${ }^{3,5,12-14)}$

이러한 상부 소화호흡기관의 증상이 인후두 역류질환 환자 들의 삶의 질을 저하시킨다는 사실이 몇몇 연구자에 의해 보 고된 바 있다. Siupsinskiene 등 ${ }^{15)}$ 은 100 명의 인후두 역류질환 환자와 109명의 건강인에서 Voice handicap index(VHI) 설 문지를 이용한 음성검사와 Hospital anxiety and depression scale을 이용한 불안과 우울 평가, visual analogue scale을
이용하여 일반적 건강감(well-being)을 평가하고 비교하였다. 이 연구에서 인후두 역류질환 환자군에서 식도염의 동반 유 무와 상관없이 건강 대조군과 비교하여 통계적으로 유의하게 $\mathrm{VHI}$ 점수가 높았으며, 불안점수가 높았고, 사회활동과 건강 감이 낮았다. 또한 삶의 질과의 관련성은 후두내시경 소견보 다 인후두 역류질환증상과 더 밀접하다고 보고하였다. Cheung 등 ${ }^{16)}$ 도 76 명의 인후두 역류질환 환자와 73 명의 건강 인에서 유사한 연구를 통해 인후두 역류질환 환자군에서 유 의하게 VHI 점수가 높았고, 36-Item Short Form Health Survey(SF-36) 설문지를 이용한 삶의 질 평가에서 사회적 기 능, 통증, 건강 인식 상태가 나빴고 우울 점수도 높았다고 보 고하였다. Carrau 등)은 117 명의 인후두 역류질환, 471 명의 위식도 역류질환, 2474명의 미국 일반인을 대상으로 SF-36 설문지를 이용한 비교 연구에서 인후두 역류질환군이 정상 군에 비해 신체 기능, 통증, 일반적 건강 인식, 활력, 사회적 기 능, 정신 건강 등 거의 모든 영역에서 유의하게 낮은 점수를 보인다는 점을 보여주었으며, 흥미롭게도 위식도 역류질환과 비교해서도 인후두 역류질환 군에서 활력, 사회적 기능이 더 낮은 점수를 보인다고 보고하였다. 또 다른 연구에서는 위식 도 역류질환군과 위식도 역류질환 및 인후두 역류질환이 함 께 있는 환자를 비교한 결과 삶의 질 항목 뿐 아니라 업무 생 산성에서도 인후두 역류질환이 동반된 환자에서 더 떨어진다 는 결과를 보고한 바 있다. ${ }^{8)}$

인후두 역류질환 환자에서 삶의 질이 저하되는 데는 몇 가 지 설명이 가능하다. 목소리와 발성은 일상 대화에서 핵심 요소로 작용하며 이와 관련된 장애는 사회적인 상호작용 및 기능에 지대한 영향을 미친다. 인후두 역류질환의 만성적인 경과를 고려해 볼 때 일상생활에서 반복적으로 나타나는 증 상은 인후두 역류질환 환자들이 느끼는 불편감을 장기화하 고 만성적인 심리적 불안정을 조장할 수 있다.) 또한 만성적 인 기침이나 인후두 청소는 그 자체로도 에너지를 소비하는 일일 뿐 아니라 환자로 하여금 조용한 장소나 타인과의 접촉 을 꺼리게 할 수 있는 요인이 된다. 또한 인두 이물감으로 인 해 식사 자체를 불편하게 느낄 수 있게 된다. ${ }^{10}$

인후두 역류질환의 치료로는 식이조절, 알칼리성 음료 음 용, 생활습관 개선, 약물치료 등이 알려져 있다. ${ }^{1718)}$ 약물치료 는 과거에는 증상의 정도에 따라 제산제, $\mathrm{H} 2$ 수용체 차단제, 위장관 운동 촉진제 등 다양하게 단계별로 권장되기도 하였 으나, 현재는 양성자펌프 억제제가 약물치료의 근간을 이루 고 있고 인후두 역류질환이 의심되는 환자에서는 경험적 치 료가 권고되고 있다. ${ }^{1,19)}$ 양성자펌프 억제제의 작용기전은 위 벽세포내의 위산분비를 차단하며, 인후두 역류질환이 확실 한 경우, 초치료로써 양성자펌프 억제제의 4주간 투여로 만 
족할 만한 증상개선의 효과가 있음이 보고되기도 하였지 만, ${ }^{20)}$ 일반적으로 인후두 역류질환에서는 위식도 역류질환보 다 더 적극적이고 장기간의 치료를 필요로 한다. ${ }^{21,22)}$ 양성자 펌프억제제의 용량과 용법에 관한 연구에서도 인후두 역류 질환 환자의 치료에 있어서 병용약물과는 무관하게 양성자 펌프 억제제 치료는 치료 1 개월 후부터 RSI를 유의하게 감소 시켰으며 평균 2.3 개월에는 대부분의 증상이 소실됨을 보고 한 바 있다. ${ }^{17}$

본 연구에서도 양성자 펌프억제제 치료 4주 후부터 RSI의 유의한 차이를 보였으며, 특히 애성, 호흡곤란, 기침, 이물감 이 현저한 차이를 보였다. 또한 치료가 지속될수록 점진적으 로 호전되는 양상을 관찰할 수 있었다. 아울러 RFS 역시 치 료 4주 후부터 발적, 성대 부종, 후두부종, 후두내 객담이 유 의한 차이를 보였으나 그 변화의 폭은 RSI 보다 작았다.

본 연구에서는 두경부 증상에 대해 더 특이적으로 고안된 EORTC-HN35 설문지를 이용하여 두경부 증상에 초점을 맞춘 삶의 질 항목을 분석하였으며, 전반적 건강 상태/삶의 질의 평가는 EORTC QLQ-C30 설문지를 이용하여 분석하 였다. 전반적 건강 상태/삶의 질은 치료전에 비해 치료 3 개월 후 유의하게 상승하였으며, 언어 문제, 구강 건조, 기침, 아픈 느낌의 항목에서도 유의한 호전을 보였다. 이전의 몇몇 연구 에서도 인후두 역류질환에서 양성자펌프 억제제 치료 후 Jitter, Shimmer, noise to harmonics ratio의 음성학적 결과 가 치료 1 개월부터 유의한 호전을 보였다고 보고된 바 있으 며,23) Lee 등의 의 연구도 인후두 역류질환 환자에서 12 주의 양성자 펌프 억제제 치료를 통해 RSI, RFS 뿐 아니라 삶의 질 척도에서 유의한 호전을 보였다고 보고한 바 있다.

본 연구의 제한점으로 인후두 역류질환은 그 진단기준이 모두가 동의하는 명확한 기준이 없어 다소 논란이 있다. 하 지만 RSI와 RFS가 많은 연구자들과 임상에서 보편적으로 사용되기 때문에 본 연구에서 진단기준으로 사용하였다. $\mathrm{RFS}$ 는 내시경 소견을 바탕으로 검사자가 판단하는 만큼 주 관적인 요소가 포함될 수 있어 검사자간 또는 검사자 내에서 도 편차가 발생할 수 있다는 단점이 있다. 하지만 본 연구에 서는 한 명의 검사자가 모든 평가를 진행하였으며, 진료 중에 평가한 RFS를 증례기록지에 기록할 때 다시 재평가함으로 써 검사자 내 편차를 최소화하기 위해 노력하였다. 둘째로, 위약을 이용한 대조군이 없어 치료 전 후의 효과가 약물치료 에 의한 것으로 단정하는데 한계가 있다. 마지막으로, 인후두 역류질환의 발생과 호전에 영향을 미칠 수 있는 동반 질환, 병용 약물, 생활습관 및 개선 정도 등에 대한 평가가 부족하 였다.

결론적으로 양성자 펌프 억제제 투여는 인후두 역류질환
의 치료에 있어서 4주 후에는 RSI, RFS의 유의한 호전을 유 발하였고, 12 주 후에 평가한 삶의 질에서도 유의한 개선을 보였다. RSI에서는 애성, 호흡곤란, 기침, 이물감과 RFS에서 는 발적, 성대 부종, 후두부종, 후두내 객담에서 변화가 유의 하였다. 따라서 임상의사는 인후두 역류질환의 치료 후 추적 관찰에 있어서 이와 같은 항목을 면밀히 관찰함으로써 환자 의 삶의 질에 대한 호전을 예측할 수 있을 것이다.

\section{Acknowledgments}

This work was supported by Hanyang University Industry-University-Research Cooperation Foundation (Project Number: 201700000002021).

\section{Author Contribution}

Conceptualization: Yong Bae Ji. Data curation: Hae-Won Choi, Hyun-Woong Jun. Formal analysis: Hae-Won Choi, Hyun-Woong Jun. Funding acquisition: Yong Bae Ji. Project administration: Kyung Tae, Yong Bae Ji. Supervision: Jin Hyeok Jeong, Moo Keon Kim, Kyung Tae. Validation: Jin Hyeok Jeong, Moo Keon Kim, Kyung Tae. Visualization: Hae-Won Choi, Yong Bae Ji. Writingoriginal draft: Hae-Won Choi. Writing — review \& editing Jin Hyeok Jeong, Moo Keon Kim, Kyung Tae, Yong Bae Ji.

\section{ORCID}

Yong Bae Ji

https://orcid.org/0000-0002-0182-7865

\section{REFERENCES}

1) Koufman JA, Aviv JE, Casiano RR, Shaw GY. Laryngopharyngeal reflux: Position statement of the committee on speech, voice, and swallowing disorders of the American Academy of OtolaryngologyHead and Neck Surgery. Otolaryngol Head Neck Surg 2002;127(1):32-5.

2) Belafsky PC, Postma GN, Koufman JA. The validity and reliability of the reflux finding score (RFS). Laryngoscope 2001;111(8):1313-7.

3) Belafsky PC, Postma GN, Koufman JA. Validity and reliability of the reflux symptom index (RSI). J Voice 2002;16(2):274-7.

4) Jung YH, Chang DY, Jang JH, Jung EJ, Hah H, Sung MW, et al. Reflux Symptom Index (RSI) and Reflux Finding Score (RFS) of persons taking health checkup and their relationship with gastrofiberscopic findings. Korean J Otolaryngol-Head Neck Surg 2007;50(5):431-7.

5) Koufman JA. The otolaryngologic manifestations of gastroesophageal reflux disease (GERD): a clinical investigation of 225 patients using ambulatory 24-hour $\mathrm{pH}$ monitoring and an experimental investigation of the role of acid and pepsin in the development of laryngeal injury. Laryngoscope 1991;101(4 Pt 2 Suppl 53):1-78.

6) Carrau RL, Khidr A, Crawley JA, Hillson EM, Davis JK, Pashos CL. The impact of laryngopharyngeal reflux on patient-reported quality of life. Laryngoscope 2004;114(4):670-4.

7) Carrau RL, Khidr A, Gold KF, Crawley JA, Hillson EM, Koufman JA, et al. Validation of a quality-of-life instrument for laryngopharyngeal reflux. Arch Otolaryngol Head Neck Surg 2005;131(4):315-20.

8) Gong EJ, Choi KD, Jung HK, Youn YH, Min BH, Song KH, et al. Quality of life, patient satisfaction, and disease burden in patients with gastroesophageal reflux disease with or without laryngopharyngeal reflux symptoms. J Gastroenterol Hepatol 2017;32(7):1336-40.

9) Lee JS, Lee YC, Kim SW, Kwon KH, Eun YG. Changes in the quality of life of patients with laryngopharyngeal reflux after treatment. J Voice 2014;28(4):487-91.

10) Lenderking WR, Hillson E, Crawley JA, Moore D, Berzon R, Pashos CL. The clinical characteristics and impact of 
laryngopharyngeal reflux disease on health-related quality of life. Value Health 2003;6(5):560-5.

11) Postma GN, Tomek M, Belafsky PC, Koufman JA. Esophageal motor function in laryngopharyngeal reflux is superior to that in classic gastroesophageal reflux disease. Ann Otol Rhinol Laryngol 2001;110(12):1114-6.

12) Belafsky PC, Postma GN, Amin MR, Koufman JA. Symptoms and findings of laryngopharyngeal reflux. Ear Nose Throat J 2002;81(9 Suppl 2):10-3.

13) Book DT, Rhee JS, Toohill RJ, Smith TL. Perspectives in laryngopharyngeal reflux: An international survey. Laryngoscope 2002;112(8 Pt 1):1399-406.

14) Noordzij JP, Khidr A, Desper E, Meek RB, Reibel JF, Levine PA. Correlation of $\mathrm{pH}$ probe-measured laryngopharyngeal reflux with symptoms and signs of reflux laryngitis. Laryngoscope 2002; 112(12):2192-5.

15) Siupsinskiene N, Adamonis K, Toohill RJ. Quality of life in laryngopharyngeal reflux patients. Laryngoscope 2007;117(3):480-4.

16) Cheung TK, Lam PK, Wei WI, Wong WM, Ng ML, Gu Q, et al. Quality of life in patients with laryngopharyngeal reflux. Digestion 2009;79(1):52-7.

17) Lee YJ, Kwak MK, Eom JH, Ji YB, Song CM, Tae K. Optimal Regimen and Period for the Treatment of Patients with Laryngopharyngeal
Reflux Disease. Korean J Otorhinolaryngol-Head Neck Surg 2014; 57(10):698-702.

18) Yang J, Dehom S, Sanders S, Murry T, Krishna P, Crawley BK. Treating laryngopharyngeal reflux: Evaluation of an anti-reflux program with comparison to medications. Am J Otolaryngol 2018;39(1):50-5.

19) Ford CN. Evaluation and management of laryngopharyngeal reflux. JAMA 2005;294(12):1534-40

20) Chung MK, Min JY, Oh JW, Jeong HS, Baek CH, Son YI. The efficacy of 4-week short-term therapy with proton pump inhibitor as an initial treatment regimen for the patients with laryngopharyngeal reflux. Korean J Otolaryngol-Head Neck Surg 2005;48(6):796-800.

21) Park W, Hicks DM, Khandwala F, Richter JE, Abelson TI, Milstein C, et al. Laryngopharyngeal reflux: Prospective cohort study evaluating optimal dose of proton-pump inhibitor therapy and pretherapy predictors of response. Laryngoscope 2005;115(7):1230-8.

22) Reichel O, Dressel H, Wiederänders K, Issing WJ. Double-blind, placebo-controlled trial with esomeprazole for symptoms and signs associated with laryngopharyngeal reflux. Otolaryngol Head Neck Surg 2008;139(3):414-20.

23) Jin bJ, Lee YS, Jeong SW, Jeong JH, Lee SH, Tae K. Change of acoustic parameters before and after treatment in laryngopharyngeal reflux patients. Laryngoscope 2008;118(5):938-41. 